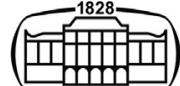

AKADÉMIAI KIADÓ

\title{
Developing a strategy for designing light in drug addiction centers
}

\author{
Nesma Sadoud ${ }^{1 *}$ and Erzsébet Szeréna Zoltán ${ }^{2}$
}

\section{Pollack Periodica \\ An International Journal \\ for Engineering and Information Sciences}

$16(2021)$ 1, 151-156

DOI:

$10.1556 / 606.2020 .00220$

(c) 2020 The Author(s)
ORIGINAL RESEARCH PAPER

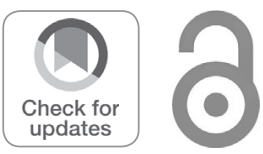

${ }^{1}$ Marcel Breuer Doctoral School, Faculty of Engineering and Information Technology, University of Pécs, Boszorkány u. 2, H-7624 Pécs, Hungary

${ }^{2}$ Department of Architecture and Urban Planning, Institute of Architecture, Faculty of Engineering, University of Pécs, Rókus u. 2, H-7624 Pécs, Hungary

Received: March 25, 2020 • Revised manuscript received: June 25, 2020 • Accepted: September 9, 2020 Published online: February 24, 2021

\begin{abstract}
The aim of this paper is to introduce the visual elements that may influence the lighting quality, and link them with the functioning of drug addiction institutes to understand the adequate design for each function and assure the well-being of the patient, therefore reduce their stress. The suggested strategy accords the qualitative and quantitative lighting design conditions to afford a complete reference for the forward study.
\end{abstract}

\section{KEYWORDS}

function, drug addiction institute, well-being, lighting design conditions

\section{INTRODUCTION}

The therapeutic and the treatment spaces must provide not only medical care but also a suitable environment that guarantees the comfort and well-being of patients during their stay there. The sense of well-being is defined as a result of the perception of the user in his environment. In other words, the well-being is influenced by the physical quality of space. So, the prevention of design mistakes, and the sensitive conception of buildings that respects the physical needs of space and users, can offer a sense of belonging and a comfortable atmosphere [1].

The earlier researches have proved that lighting design is a crucial element that can impress the mood released by the environment positively or negatively. The light as an element has the ability to define the identity of the place and make it clearer for the user, consequently assuring his well-being, as well as the lighting design, is recommended as the solution for the existing building with visual problems [2].

So lighting is not just a standard calculation is a concept that occupants can perceive it and be affected by its emitted atmosphere. Thereby the failure in lighting design might cause displeasure and fatigue, while good lighting design can satisfy and makes users more productive [3]. As well as the existence of the lighting effect was also confirmed by Veitch and Newsham's proposal [4] that mentions the presence of lighting quality must be compatible with the conditions needed in a place.

However, these previous studies lack in-depth understanding, mainly regarding addiction centers and the specific needs of this type of institute. Adopting light in this research means not only the quantitative part as the luminance, since this approach does not study the emotional effect of lighting, but only evaluates its technical integrity. The interest is preferably on both the technical part and emotional lighting design, where this last is measured through the spatial function, the physical composition, and the occupants' state [5]. 
In this context, the suggested methodology offers visual comfort and the possibility of understanding the space by focusing on the artificial lighting design. It based on the involvement of the functional program of the selected case study and the spatial characteristics collected from previous experimentations (Fig. 1). The methodology consists of framing the spatial elements adopted with the architectural visual terms, which makes the research cover in all aspects the optical factors of light to achieve visual comfort in these addiction centers.

The paper proposes to collect a database for further research to be able to compare the existing spatial characteristics in the case studies and the factors adopted in this research. Therefore, it can be possible to solve the physical quality problems of these existing buildings and provide visual comfort to patients by focusing on the lighting factor, as well as making new concepts in this field.

\section{METHODOLOGY}

According to the previous results about the influence of the physical environment on the addicts' perception, it was approved that daylight is one of the essential elements that affect spatial quality. The inadequacy of this variable caused indoor visual issues, which lead this paper to suggest the lighting design as a solution to recompense this insufficiency of natural light within this existing institute [5].

The light quality differs between bad lighting, neutral, and good lighting, this research aims to introduce procedures to ensure proper lighting quality for forwarding studies [6].

\subsection{The elements that define spatial quality in relation to light}

\section{a) The spatiality}

This factor determines the elements that make up the physical space and the way that they can affect the quality of light perceived by users. According to the previous investigation about space's quality of drug addiction establishment; the parameters of the enclosure, the window orientation, and the natural light have a noticeable impact on the spatial quality of the rooms, and therefore on the perception of the users $[5,6]$.

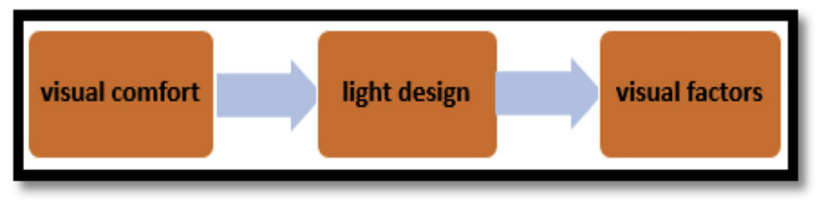

Fig. 1. The conceptual paths to achieve the visual comfort in drug addiction centers b) The atmosphere

The atmosphere is linked to the mood that light creates in the space [5]. The previous studies recommended providing a domestic atmosphere for the psychiatric centers, which is far from having it when using fluorescent tube light, which gives a much more commercial and institutional aspect, and this is the case for the selected institute [7]. The present study suggests involving the impression that is aroused by lighting to improve the mood of patients (clarity, spaciousness, relaxation, privacy, pleasantness, communication). The spatial impression could be affected too by the cultural background of users, [6-9].

c) The visibility

This part is connected to the clarity of the area during the accomplishment of the tasks and this is related to many parameters that could influence the lighting visibility. The paper adopts the standards of visual light for the addiction center functions [6].

\subsection{The case study}

The institute is a French construction (French heritage since the 20th century) [10]. It's picked in this study was selected from different establishments that were presented in the first step of research for the architectural analysis of drug addiction centers, where this analysis was based on three scopes that are, the sociohistorical, functional, and spatial aspects. After these evaluations, gaps are found in certain of these centers, which make it difficult to complete the study and extract recommendations with the presence of gaps at other levels. Taking into consideration that this research specializes only in the in-depth evaluation of the interior space aspect with verification of differences and other shortcomings so that the result is more logical. This center was the most appropriate for choosing it as a reference to perform the procedures since its main problem is spatial quality [5].

This phase is based on enumerating the spaces in the center and classifying them according to their function in order to merge each space with the proposed optical elements for light design (Fig. 2).

\subsection{The light description of the case study}

The lighting system adopted in this center is a direct light by the fluorescent tube, and the only artificial light source is through the ceiling (Figs 3 and 4, Table 1), which gives standardization to all spaces as this type of light is not appropriate for psychiatric spaces because it eliminates its warm and emotional impression [11].

\subsection{The relationship between physical elements and the light quality of the space}

The physical elements of space are a composition linked to each other where the observer perceives it as a single entity, and not composed, for this reason, it is necessary to study all of these features. On the other hand, the mode of light has a significant impact on the perception of space, and in turn, the elements of space affect the quality of light [12]. 


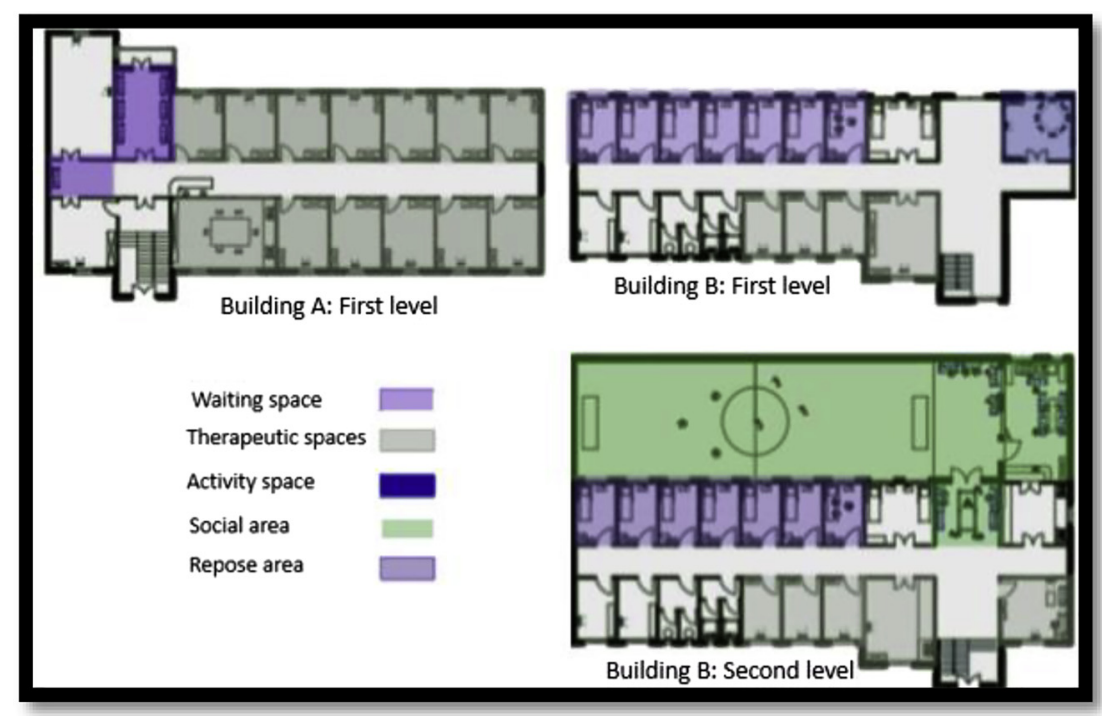

Fig. 2. The existing function of the case study

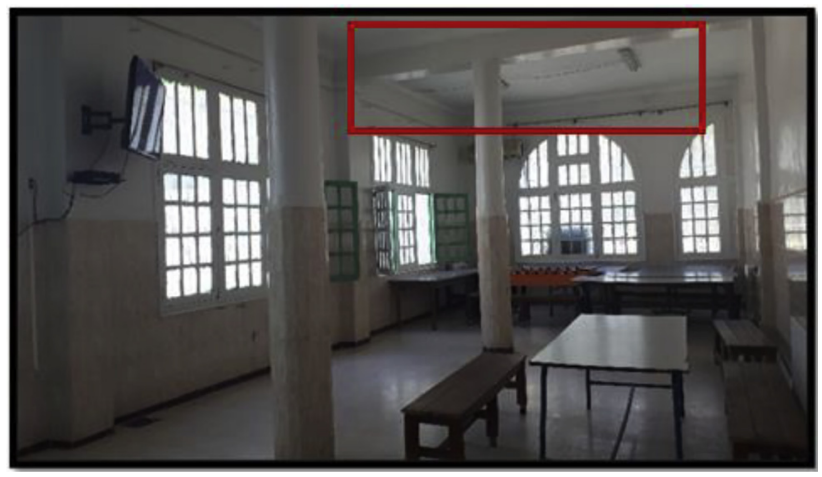

Fig. 3. The lighting system in the institute
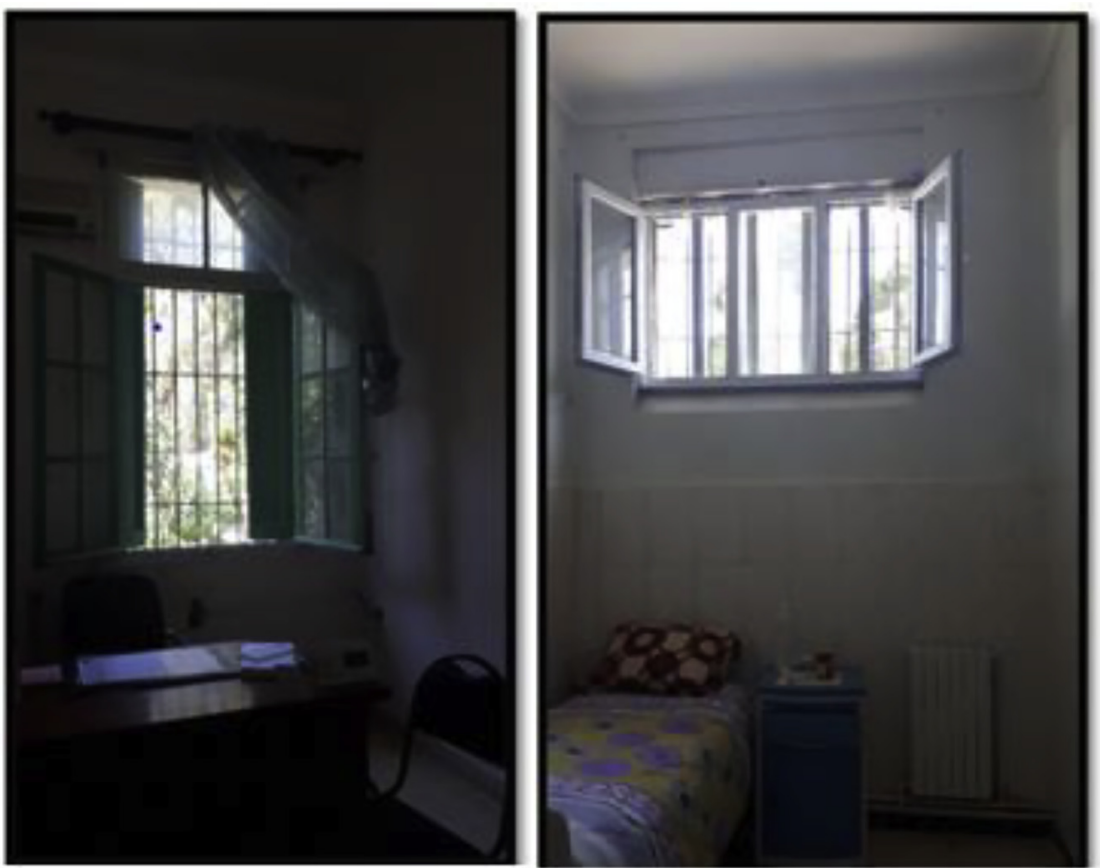

Fig. 4. The lighting system in the institute

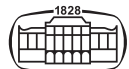


Table 1. The lighting system in different rooms of the institute

\begin{tabular}{lcc}
\hline $\begin{array}{l}\text { The center's } \\
\text { spaces }\end{array}$ & $\begin{array}{c}\text { The Functional } \\
\text { aspect }\end{array}$ & The lighting system \\
\hline $\begin{array}{l}\text { Bedrooms } \\
\text { Playing area } \\
\text { TV and eating } \\
\text { room }\end{array}$ & $\begin{array}{c}\text { Repose area } \\
\text { Social area }\end{array}$ & $\begin{array}{c}\text { Daylight }+ \text { fluorescent tube } \\
\text { in the ceiling }\end{array}$ \\
$\begin{array}{l}\text { Courtyard } \\
\text { Ergo therapy } \\
\text { room }\end{array}$ & Activity space & \\
$\begin{array}{l}\text { Waiting room } \\
\text { Waiting space }\end{array}$ & Waing \\
\hline
\end{tabular}

The main concern of this conception is to avoid the stressful elements for patients and invigorate their satisfaction.

The homely or domestic feelings are one of the important sensations that could help patients during they healing time in the hospital to be more comfortable and it could be afforded by the material use (natural material as wood), as well as the avoidance of strong contrast in textures and motifs should be taken into consideration because it may cause more stress for patients, $[13,14,16]$.

\subsection{Space and its relevance to the patient's impression}

The functions of the center divided into repose area, common area, activity space, waiting and treatment space. Each area has a role in the daily routine of patients and it is required to assure their satisfaction and their well-being. The light design is supposed to create an adequate atmosphere according to the functioning of the space. The waiting space, for example, should release relaxing and spacious impressions for the patients to reduce the feeling of anxiety during the waiting period, which might seem long for them. Unlike the bedrooms that must provide a feeling of privacy for the well-being of patients, by keeping the room appear a bit enclosed $[13,14,16]$.

\subsection{The visibility and functioning}

This part is technical, it goes to the quantitative aspect in order to have a more real, and applicable result, it serves to support the theoretical side of the method and it is based on the standards of the therapeutic centers (Table 2) $[14,16$, 17].

Table 2. The illuminance standard for each function

\begin{tabular}{lcc}
\hline $\begin{array}{l}\text { The center's } \\
\text { spaces }\end{array}$ & $\begin{array}{c}\text { The Functional } \\
\text { aspect }\end{array}$ & $\begin{array}{c}\text { The standard } \\
\text { illuminance }\end{array}$ \\
\hline $\begin{array}{l}\text { Bedrooms } \\
\text { Playing area } \\
\text { TV and eating } \\
\text { room }\end{array}$ & $\begin{array}{c}\text { Repose area } \\
\text { social area }\end{array}$ & $\begin{array}{l}200 \text { lux } \\
\text { Ergo therapy } \\
\text { room }\end{array}$ \\
$\begin{array}{l}\text { Waiting room } \\
\text { Activity space }\end{array}$ & 200 lux \\
& waiting space & 200 lux \\
\hline
\end{tabular}

\subsection{The selected lighting characteristics and their effect on the perception of the areas}

After selecting the aim of the paper, which consists of the evaluation of the patients' visual comfort by giving an identity to space through the light, it was possible to identify the adequate lighting variables for this study and linked them with the factors mentioned above [7].

- Lighting position: the position of the light has an influence on the luminous flux and the quality of space, in certain studies the localization of the light source called; the lighting topography;

- The type of light: it is about the distribution of light, how it could illuminate the space it is varied between uniform and not uniform lighting system;

- Brightness: it is about the intensity perceived in the space each functioning required a specific brightness level; it is divided between bright and dim lighting.

\subsubsection{The lighting parameters and the impressions in rest} areas. According to doctors' discussion, the bedrooms of this center are just for spending the night and sleeping, and it is not recommended for patients to stay there many times, due to their psychological state. Through these testimonies and the previous knowledge about sleeping disturbance and its adverse outcomes, this area must emit a private impression and comfort to give the patient a homey feeling and contribute to their relaxation during their period of rest, [7, 14, 16].

It revealed that the combination of low luminance of light with a warm white temperature, no uniform lighting system, and peripheral lighted walls create a domestic atmosphere, comfort, and relaxation, and give the room the appropriate function of resting. To intensify the patient's sensation of comfort, it is so important to allow them to control the conditions of their environment [18].

\subsubsection{The lighting parameters and the impressions in the} exercise spaces. The motor activity place must advocate the interaction of the appeasement and the capacity of concentration, for the light design the clarity of space is too important to boost the activity and the performance of patients and their pleasantness, a high illuminance with a cold lighting temperature contribute for the alertness of users; the creation of clarity impression required a uniform horizontal and peripheral lighting system too for good visual tasks [19, 20].

\subsubsection{The lighting parameters and the impressions in the} respite places. The lighting requirement for indoor free time spaces is divided according to space activity, the center contains an indoor play area and seating area for TV, communication, and eating.

Since the play zone is for the manual activities, it should be stimulating and pleasant for patients to provide the appropriate need of space, the lighting design in this area is suggested to play on the stimulation and clarity as is 
mentioned above, the height illuminance with cold lighting temperature have an important effect on the alertness of users as well as a general horizontal lighting and a bright wall are preferred to reinforce the clarity of space and make it more pleasant.

The seating area is for relaxation and communication the role that the lighting design should afford is an atmosphere of comfort, pleasantness, and relaxation. An augmented lighting level with a warm white is revealed for affecting the impression of comfort and pleasantness, as well as, the peripheral lighting and a no uniform distribution contribute to enhance the relaxed feeling [18].

\subsubsection{The lighting parameters and the impressions in the} waiting space. The waiting area in the addiction center must be well designed to reduce the stress of patients during their waiting time. This area is for a public occupation, and it must emit an impression of spaciousness and comfort. In the field of lighting design, the perception of a spacious space is related to lighting distribution, position, and illumination level. High bright walls and horizontal plans with a uniform light contribute to producing a spacious impression of space. At the same level, the tone of light does not affect the size perception, which leads to suggest a warm light temperature to enhance the comfort sensation [18].

\section{DISCUSSION}

According to the studies and the data collected from different researches, it is noticeable that there is a glaring difference between the standards of light that guarantee only the visual tasks in the place, and the design of light that can offer an identity to space and ensure the well-being. From this contradiction and the aim of the investigation, which is the assurance of visual comfort and the well-being of patients, the focus will be oriented on the qualitative side and contain the standard side to not fall into insufficient lighting.

After all the investigations and information gathered, this article managed to create a structure that helps to understand the relationship between light perception and the components of the surrounding environment (Fig. 5).

\section{CONCLUSION}

This paper attempts to create a model of lighting design for addiction centers based on three main factors. These factors cover the technical and psychological parts in order to reduce the luck and converge the distance between the quantitative and qualitative parts. The basements of these factors are collected from the previous experiment and research realized about the psychiatry, hospitals, and therapeutic centers with taking into consideration the patient's psychology and the functioning of addiction centers.

The method contributes in the understanding of lighting design preference, the user preferred a high luminance cleared place, but the question is which conditions of light could assure the satisfaction and the wellbeing of patients. Which type of lighting is suitable for the functioning of rooms and how and how it is possible to evaluate these existing places and solve the visual problems?

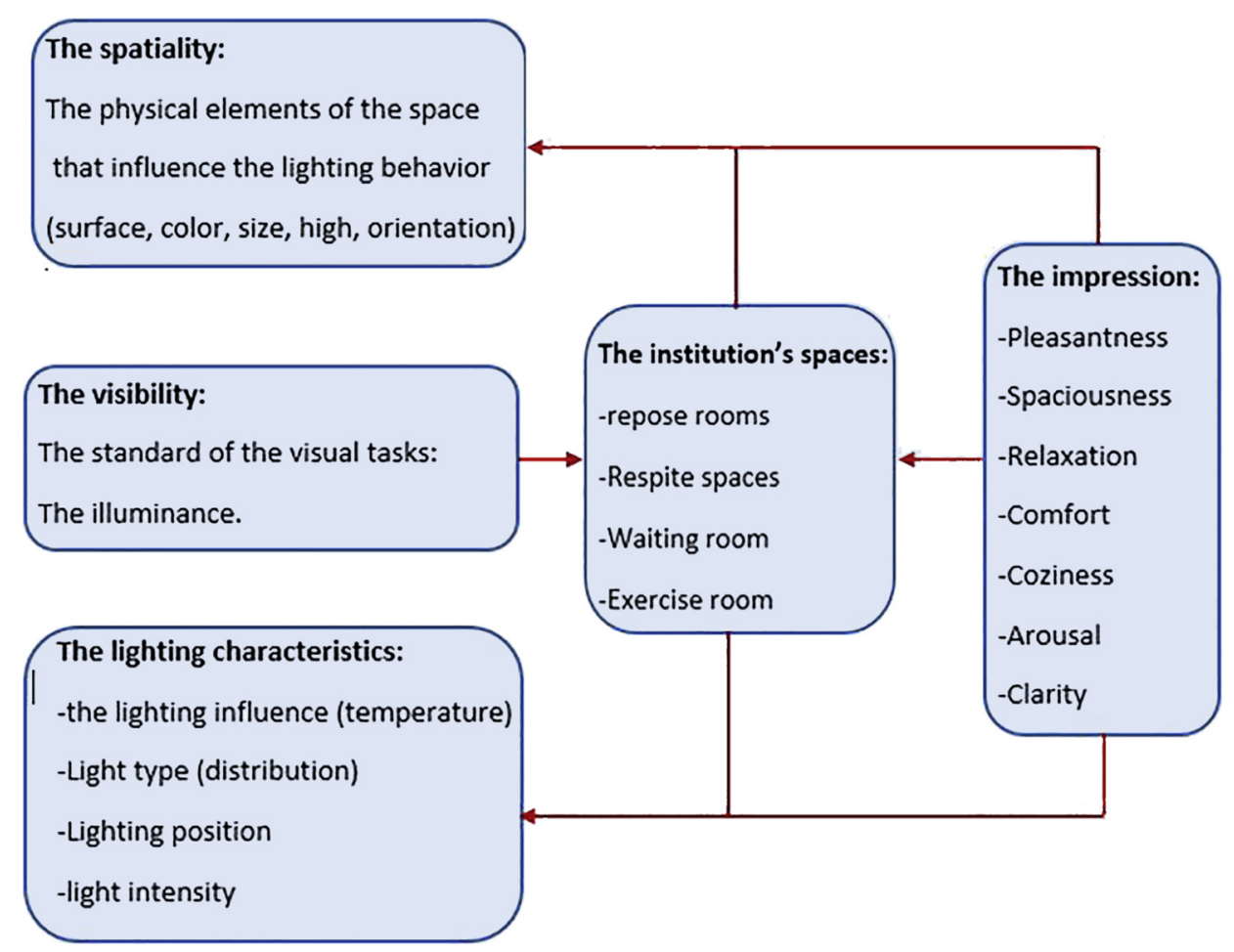

Fig. 5. The conceptual model that relate the institute's spaces with the visual factors of lighting design 
The model suggested could be a reference for further study to collect the necessary database related to these visual terms for studying and comparing the lighting issue as well as bringing new knowledge to the field of addiction centers design.

\section{REFERENCE}

[1] X. Li, How Architecture Can Promote a Sustainable and Therapeutic Experience for Patients in Psychiatric Hospitals in China. NY: Rochester Institute of Technology, 2018.

[2] Light for health and care, Zumtobel, 2015. [Online]. Available: https://www.zumtobel.com/PDB/Teaser/EN/AWB_Health_Care. pdf. Accessed: June 26, 2020.

[3] R. Küller, "Planning for good indoor lighting," Lund University, Sweden, Research Report, 2004.

[4] J. A. Veitch, "Psychological processes influencing lighting quality," J. Illum. Eng. Soc., vol. 30, no. 1, pp. 124-140, 2001.

[5] C. V. Fontenelle, "The importance of lighting to the experience of architecture," Architecture Quality Issues, KTH Royal Institute of Technology, Stockholm, Sweden, 2008, pp. 1-14.

[6] L. M. Stidsen, "Light atmosphere in hospital wards," $\mathrm{PhD}$ Thesis, Aalborg University, Denmark, 2013.

[7] A. Durak, N. C. Olguntürk, C. Yener, D. Güvenç, and Y. Gürçınar, "Impact of lighting arrangements and illuminance on different impressions of room," Build. Environ., vol. 42, no. 10, pp. 34763482, 2007.

[8] P. Kovács, B. Kósa, and T. Molnár, "NEST - A sacred space designed for all," Pollack Period., vol. 13, no. 3, pp. 11-18, 2018.

[9] H. Barbara and T. Molnar, "Towards understanding the colonial heritage in Algeria: The case of the Sheridan Villa," Pollack Period., vol. 14, no. 1, pp. 223-234, 2019.
[10] K. Connellan, M. Gaardboe, D. Riggs, C. Due, A. Reinschmidt, and L. Mustillo, "Stressed spaces: mental health and architecture," Health Environ. Res. Des. J., vol. 6, no. 4, pp. 127-168, 2013.

[11] R. Reiz, R. Busa-Fekete, A. Pongor, and I. Kovács, "Closure enhancement in a model network with orientation tuned longrange connectivity," Learn. Percept., vol. 5, suppl. 2, pp. 119-148, 2013.

[12] E. Chrysikou, Architecture for Psychiatric Environments and Therapeutic Spaces. IOS Press, 2014.

[13] T. Hwang and T. J. Kim, "Effects of indoor lighting on occupants' visual comfort and eye health in a green building," Indoor Built Environ., vol. 20, no. 1, pp. 75-90, 2011.

[14] R. S. Ulrich, L. Bogren, S. K. Gardiner, and S. Lundin, "Psychiatric ward design can reduce aggressive behavior," J. Environ. Psychol., vol. 57, pp. 53-66, 2018.

[15] A. Galatioto and M. Beccali, "Aspects and issues of daylighting assessment: A review study," Renew. Sustain. Energy Rev., vol. 66, pp. 852-860, 2016.

[16] Whitecroft lighting, healthcare lighting. [Online]. Available: https://docplayer.net/37408751-Whitecroft-lighting-healthcarelighting.html. Accessed: Dec. 10, 2019.

[17] S. Mehrotra, S. Basukala, and S. Devarakonda, "Effective lighting design standards impacting patient care: a systems approach," J. Biosci. Med., vol. 3, pp. 54-61, 2015.

[18] S. Odabaşığlu and N. Olguntürk, "Effects of colored lighting on the perception of interior spaces," Perceptual Mot. Skills, vol. 120, no. 1, pp. 183-201, 2015.

[19] E. Demilly, "Autism and architecture relations between architectural forms and the clinical condition of patients," (in French) PhD Thesis, University Lyon II, 2014.

[20] N. Sadoud, "The architecture of addiction institutions and its influence on patients' behavior," in 6th International Academic Conference on Places and Technologies, Pécs, Hungary, May 9-10, 2019, 2019, pp. 524-532. 